\title{
PERFIL DAS PREFEITURAS QUE DESCENTRALIZARAM O PELC DE 2003 A $2012^{1}$
}

Recebido em: 09/02/2017

Aceito em: 10/11/2017

\author{
Edmilson Santos Santos \\ UNIVASF \\ Petrolina - PE - Brasil
}

Fernando Augusto Starepravo

Universidade Estadual de Maringá

Maringá - PR - Brasil

Edson Hirata

UTFPR - Campus Campo Mourão

Campo Mourão - PR - Brasil

RESUMO: Passados mais de dez anos do início da implementação do Programa Esporte e Lazer da Cidade do Ministério do Esporte, há uma lacuna na literatura de políticas públicas de esporte e lazer no que diz respeito às quais prefeituras conseguem descentralizar o programa. Esse trabalho, de natureza descritiva, surge com objetivo de traçar perfil dos municípios implementadores do PELC. Destaca-se o baixo número de convênio com os municípios, prevalecendo os das regiões Norte, Sudeste, Sul e CentroOeste; municípios de maior porte populacional; com IDH Baixo ou Muito Baixo. Dentre os municípios que estabeleceram mais de quatro convênios destacam-se: municípios da capital, das regiões metropolitanas e do estado do Rio Grande do Sul.

PALAVRAS CHAVE: Políticas Públicas. Esportes. Atividades de Lazer. Descentralização.

\section{PROFILE OF CITY HALLS THAT DECENTRALIZED PCSL BETWEEN 2003 AND 2012}

ABSTRACT: Over ten years after the beginning of the Program City's Sport and Leisure (PCSL) implementation, there is a gap in literature about public policies in sport and leisure regarding city halls able to decentralize the program. This descriptive study emerges with the goal of outlining the profile of municipalities that have implemented the PCSL. It points out the low number of alliances with the municipalities, prevailing

\footnotetext{
${ }^{1}$ Pesquisa financiada pelo Ministério do Esporte e desenvolvida pelo Centro de Desenvolvimento de Pesquisa em Políticas de Esporte e de Lazer da Rede Cedes Piauí em parceria com o Grupo de Estudos e Pesquisa em Políticas Públicas de Esporte e Lazer da UEM.
} 
the ones from regions North, Southeast, South and Midwest, with higher populational scores and Low or Very Low HDI. Among the municipalities that have established more than four alliances, capital cities, municipalities from the metropolitan area and from the state of Rio Grande do Sul stand out.

KEYWORDS: Public Policies. Sports. Leisure Activities. Decentralization.

\section{Introdução}

O ordenamento constitucional não indicou responsabilidades aos entes federados no que diz respeito à implementação de políticas de esporte e de lazer. Diferentemente de alguns autores que interpretam o direito colocado na Constituição Federal de 1988 (CF/88) como um dever abstrato de todos (BONALUME, 2011; MENDES; AZEVÊDO, 2010; TERRA et al., 2009; LINHALES, 1998), a própria Constituição equacionou esse problema. Primeiro, apontou no Art. 21 as competências exclusivas da União e no Art. 22 as competências legislativas privadas à União. Em nenhum dos dois artigos está colocado que compete à União formular ou implementar políticas públicas de esporte e de lazer. Em relação a esse tema, também não foi garantida competência exclusiva para outros entes federados subnacionais (estados, Distrito Federal e municípios).

Não havendo competência exclusiva, há a possibilidade de garantir competências comuns (Art. 24 da $\mathrm{CF} / 88$ ). A finalidade das competências comuns é forçar os atores federados a concorrer entre si pela melhor política, aspecto que melhoraria a eficiência da política pública, ou agir cooperadamente a fim de diminuir custos de transação.

A concorrência permite que cada um dos três entes federados possa apresentar políticas com o mesmo objetivo ou foco com vista a permitir ao cidadão reconhecer as melhores práticas e competências políticas. Já a cooperação poderia ser horizontal ou 
vertical. A cooperação vertical ocorre quando níveis federados diferentes cooperam para implementar uma política. O Programa Esporte e Lazer da Cidade (PELC) é um exemplo. O governo central formulou a política e estados e municípios a implementam. A cooperação horizontal é quando entes federados do mesmo nível cooperaram entre si para enfrentar uma dada agenda política. O exemplo são consórcios municipais relacionados ao tratamento do lixo.

Ao auferir autonomia política e recursos fiscais aos entes federados ${ }^{2}$ a $\mathrm{CF} / 88$ garantiu, em tese, condições para ofertarem políticas conforme suas preferências. Preferências essas do ator político central, o gestor, ou das instituições que têm capacidade de afetar as escolhas públicas (SECCHI, 2011).

A descentralização da política por concorrência ou por cooperação foi o instrumento estabelecido pela $\mathrm{CF} / 88$ para enfrentar, entre outras, as políticas públicas de esporte e de lazer. Há dois modelos de descentralização: a descentralização de competência, realizadas por leis complementares à Constituição, onde se transfere para instâncias subnacionais funções e recursos (como exemplo FUNDEB e SUS ${ }^{3}$ ); ou a descentralização da política definida por um ente federado superior. As políticas de esporte compõem o segundo grupo. Não existem mecanismos constitucionais que obriguem um ente federado inferior a aceitar a agenda política de um ente federado superior. As decisões políticas que não foram embasadas por texto legal estão sob a decisão discricionária dos governos e, portanto, não há imposição nessa forma de descentralização.

Não havendo imposição, a mudança de comportamento do ator descentralizador é afetada pelos incentivos que o ente superior oferta pela descentralização de uma dada

\footnotetext{
${ }^{2} \mathrm{O}$ Brasil é o país mais descentralizado do mundo do ponto de vista fiscal (ARRETCHE, 2010).

${ }^{3}$ São reconhecidas como políticas de Estado.
} 
política (quais as vantagens para descentralizar). O PELC foi formulado pela Secretaria Nacional de Desenvolvimento do Esporte e Lazer (SNDEL), atual Secretaria Nacional de Esporte, Educação, Lazer e Inclusão Social (SNELIS) do Ministério do Esporte, em 2003, para proporcionar práticas de atividades físicas, culturais e de lazer. O "Mapa dos municípios brasileiros, esporte" (IBGE, 2006) aponta com precisão as lacunas existentes no cenário nacional à democratização das atividades esportivas e de lazer, o que, por si só, já justifica políticas como o PELC.

Os incentivos para a descentralização estão, num primeiro momento, associados à oferta de recursos novos aos municípios e estados, que sempre estão em busca de mais recursos para incrementarem a oferta de políticas públicas. O recurso para sua implantação vem na forma de um pacote: material esportivo, recurso para pagamento de profissionais, formação, atividades assistemáticas e um programa já desenhado para ser implementado. O que se coloca nesse momento é se esses incentivos são suficientes para garantir a democratização do esporte e do lazer.

Na literatura da área da Educação Física há carência de estudos preocupados em avaliar o desempenho nacional do programa. Nesse cenário destacam-se Athayde, Mascarenhas e Salvador (2015), Matias (2014) Areias e Borges (2011), Starepravo (2011), Goellner et al. (2010), Sousa et al. (2010) e Vieira e Silveira (2010). No entanto, pouco se conhece sobre a participação das prefeituras na implementação do programa e sobre os municípios descentralizadores. Passados dez anos, torna-se importante traçar o perfil das prefeituras que implementaram o PELC de 2003 a 2012.

Para tanto, o estudo foi organizado em quatro momentos, além da introdução. Num primeiro momento, discutir os efeitos da descentralização. Em seguida, 
apresentação da metodologia e discussão dos resultados. Por último, as considerações finais.

\section{Descentralização de Políticas}

Descentralização pressupõe que uma determinada ação antes levada a cabo por um agente central, distante do ambiente onde a política é implementada, seja deslocada para o local de implementação. A descentralização pode ser feita por dispositivos legais imputando responsabilidades ao ente federado local, no nosso caso as prefeituras, ou por dispositivos negociados. No primeiro, há o deslocamento da capacidade de decidir sobre o conteúdo da política e sua pertinência (ALMEIDA, 1995). Nesse caso, a descentralização implica na distribuição ou transferências de funções e recursos a governos e organizações (RIBEIRO; FARIA, 2013). No último caso, não há como haver imposições ou obrigações, mas sim duas partes negociam os termos da implementação.

$\mathrm{Na}$ descentralização negociada o governo central decide sobre conteúdo e formato da política e os governos subnacionais são responsáveis pela execução de políticas (ALMEIDA, 2005). Essa ação, quando coordenada pelo governo central, deve ser direcionada para diminuir desigualdades (MARQUES; ARRETCHE, 2003), pois permite a oferta de incentivos seletivos de forma a debelar uma dada situação de desigualdade ou injustiça. Para Rodden (2005) e Arretche e Marques (2007) não é condicional ao federalismo e à descentralização os ganhos de eficiência e accountability. Nesse sentido, a descentralização pode manter ou ampliar desigualdades.

Como sabemos, os governos municipais variam fortemente em sua capacidade de implementar políticas, especialmente as sociais (SOUZA, 2001). Para alguns essa 
realidade está associada à diversidade na capacidade de financiamento dos municípios. Aqueles mais pobres são dependentes das transferências constitucionais, sobremaneira o Fundo de Participação dos Municípios (FPM). Esse fundo tem efeito redistributivo, premia os municípios mais vulneráveis com uma quantia maior de valores.

O ordenamento constitucional garantiu a descentralização das políticas de educação e de saúde. As políticas de esporte não receberam esse tratamento. Elas foram inscritas no texto constitucional para serem objetos da política (políticas de governo) e não da norma (políticas de Estado). Portanto, cabe aos gestores, em cooperação ou em concorrência, ofertarem (ou não ${ }^{4}$ ) as políticas de esporte e de lazer.

A tomada de posição envolve optar por fazer algo e mudar uma realidade ou optar por nada fazer e manter o status quo (SECCHI, 2011). Duas posturas legitimadas pelo império da lei. Os Estados só estão obrigados a fazer aquilo que está expresso na norma. O resultado desse contexto é a possibilidade de se produzir vazios assistenciais (SANTOS; STAREPRAVO; SOUZA NETO, 2015) - áreas que acabam não tendo acesso à política.

A mobilização dos municípios em direção à política está associada aos incentivos e ao julgamento da pertinência da implementação. Muitas vezes somos conduzidos a pensar que os municípios são omissos em relação a essa realidade, mas essa postura, diante da ambiguidade de qual ator federal deve fazer algo, é legitimada pelo Estado.

Por outro lado, não descentralizar uma política do governo central não significa que nada está sendo feito. Dados disponibilizados pelo Centro de Desenvolvimento de Pesquisa em Políticas de Esporte e de Lazer da Rede Cedes do Piauí sobre

\footnotetext{
${ }^{4}$ A inação não constitui uma ilegalidade ou negação do Estado de Direito. É uma possibilidade legitimada pelo texto constitucional que é a fonte de todo o direito.
} 
financiamento das políticas de esporte e lazer através da Função Desporto e Lazer, por exemplo, dão conta de que os municípios têm sido ativos no direcionamento de recursos para essas áreas ${ }^{5}$.

Passados dez anos de sua implementação, tempo suficiente para acomodar e consolidar as estratégias de implementação do PELC, torna-se relevante conhecer o perfil dos municípios que conseguiram desenvolver o programa ${ }^{6}$, o que, em última instância, nos permite avaliar o impacto e amplitude do programa.

\section{Metodologia}

Esse estudo de natureza descritiva buscou levantar o perfil das prefeituras que descentralizaram o PELC a partir das seguintes variáveis: região do país, estado ${ }^{7}$, nível de desenvolvimento humano e classe populacional. Essas variáveis permitem conhecer com maior precisão a característica das prefeituras que obtiveram sucesso no processo de seleção das propostas. Nesse caso, são prefeituras que representam a verdadeira política que, apesar de toda a retórica que a justifica, se traduz em realidade na implementação ${ }^{8}$.

\footnotetext{
${ }^{5}$ Em 2003, ano de criação do PELC, 4.457 (80,1\%) municípios investiram na Função Desporto e Lazer (FDL). Em 2012, esses investimentos na FDL alcançaram 86,1\% $(n=4.791)$ dos municípios.

6 A entidade interessada em implantar um PELC, seja prefeitura, governo estadual, universidade ou entidade privada sem fins lucrativos deve encaminhar um projeto ao Ministério do Esporte, que avalia documentação, viabilidade técnica, administrativa e orçamentária. Assim que aprovado por uma comissão técnica, o projeto passa por alguns trâmites legais até a liberação dos recursos financeiros (BONALUME, 2011).

${ }^{7}$ Da população do estudo foram retirados os convênios realizados com o Governo do Distrito Federal, pois ele não permite comparação com a unidade município.

${ }^{8} \mathrm{O}$ modelo esquemático com que fomos acostumados a pensar a implementação faz com que ela seja apenas uma etapa onde o que foi desenhado e decidido acontece. Principalmente em federações há uma distância substantiva entre o que foi decidido e formulado do que será implementado. Dado o resultado da implementação é possível se dizer que ela é a política mesma (RUA, 1997).
} 
Os dados referentes às prefeituras que descentralizaram o programa de 2003 a 2012 foram fornecidos pelo Ministério do Esporte ${ }^{9}$. As informações referentes às regiões, aos estados, ao Índice de Desenvolvimento Humano (IDH) e à classe populacional foram capturadas diretamente no site do Instituto Brasileiro de Geografia e Estatística (IBGE) tendo como base as projeções para o ano de 2010.

O estudo seguiu a classificação do IDH de forma a garantir cinco níveis: IDH Muito Alto, acima de 0,800; IDH Alto, de 0,700 a 0,799; IDH Médio, de 0,600 a 0,699; IDH Baixo, de 0,500 a 0,599; IDH Muito Baixo, abaixo de 0,499. A classe populacional (CP) seguiu aquela desenvolvida pelo IBGE, a saber: CP1, de 0 a 5 mil habitantes; CP2, de 5.001 a 10 mil habitantes; CP3, de 10.001 a 20 mil habitantes; CP4, de 20.001 a 50 mil habitantes; CP5, de 50.001 a 100 mil habitantes; CP6, de 100.001 a 500 mil habitantes; CP7, acima de 500.001 habitantes.

As informações compuseram banco de dados e foram submetidas à estatística descritiva através do Programa SPSS versão 17.1. Como a unidade de análise é o município, para os dados do perfil não se valorizou o número de vezes que foi contemplado. Apenas num segundo momento que esses dados foram escriturados a fim de permitir melhor compreensão da realidade de descentralização do PELC.

\section{Análise dos Resultados}

No que diz respeito à distribuição regional, como expressa na tabela 1, foi possível observar que em apenas uma região, a Norte, um estado, o Amapá, não descentralizou o programa através de suas prefeituras. Em todas as outras regiões a participação dos estados foi integral. O melhor resultado regional foi da região Norte,

\footnotetext{
${ }^{9}$ Lei de Acesso à Informação no 58750000093201645.
} 
mesmo assim não conseguiu mobilizar mais que 5,77\% $(n=26)$ dos municípios. A segunda colocação ficou com a região Sul, 5,29\% $(n=63)$. Foram as únicas regiões que ultrapassaram a barreira dos 5\%.

Mesmo reconhecendo o baixo desempenho das regiões na descentralização do programa, não deixa de ser um aspecto positivo que o melhor tenha se dado numa das regiões mais vulneráveis do Brasil, região Norte. Por outro lado, como aspecto negativo, temos o baixo desempenho da região Nordeste que possui o maior número de municípios vulneráveis. As regiões Norte e Nordeste são reiteradamente citadas como as mais pobres do Brasil, como apontado em Miranda e Mendes (2004). A natureza das políticas sociais vislumbra diminuir desigualdades (Inciso 3 do Art. 3 da $\mathrm{CF} / 88$ ) de acesso a políticas públicas. Nesses dez anos de implementação o PELC ajudou a promover mais desigualdade na medida em que a última colocação em percentual de participação dos municípios no PELC foi a região com maior número de municípios vulneráveis, a Nordeste.

Tabela 1: Distribuição regional e estadual do PELC de 2003 a 2012

\begin{tabular}{|c|c|c|c|c|}
\hline Região & Estados & $\mathrm{N}^{\mathrm{o}}$ Municípios & Adesão PELC & \% adesão PECL \\
\hline \multirow{7}{*}{ Norte } & AM & 62 & 3 & 4,84 \\
\hline & $\mathrm{AC}$ & 22 & 4 & 18,18 \\
\hline & AP & 16 & 0 & 0,00 \\
\hline & $\mathrm{PA}$ & 143 & 9 & 6,25 \\
\hline & $\mathrm{RO}$ & 52 & 6 & 11,54 \\
\hline & TO & 139 & 2 & 1,44 \\
\hline & RR & 15 & 2 & 13,33 \\
\hline \multicolumn{2}{|c|}{ Sub. Total } & 449 & 26 & 5,77 \\
\hline \multirow{9}{*}{ Nordeste } & $\mathrm{AL}$ & 102 & 1 & 0,98 \\
\hline & $\mathrm{BA}$ & 417 & 12 & 2,88 \\
\hline & $\mathrm{CE}$ & 184 & 4 & 2,17 \\
\hline & MA & 217 & 6 & 2,76 \\
\hline & PB & 223 & 3 & 1,34 \\
\hline & $\mathrm{PE}$ & 185 & 9 & 4,86 \\
\hline & PI & 224 & 6 & 2,68 \\
\hline & $\mathrm{RN}$ & 167 & 7 & 4,19 \\
\hline & $\mathrm{SE}$ & 75 & 1 & 1,33 \\
\hline \multicolumn{2}{|c|}{ Sub. Total } & 1794 & 49 & 2,73 \\
\hline Sudeste & ES & 78 & 3 & 3,85 \\
\hline
\end{tabular}




\begin{tabular}{c|c|c|c|c}
\hline \multirow{4}{*}{} & MG & 853 & 29 & 3,40 \\
\cline { 2 - 5 } & RJ & 92 & 14 & 15,22 \\
\cline { 2 - 5 } & SP & 645 & 39 & 6,05 \\
\hline \multicolumn{2}{c|}{ Sub. Total } & 1668 & 46 & 4,50 \\
\hline \multirow{3}{*}{ Sul } & PR & 399 & 15 & 3,76 \\
\cline { 2 - 5 } & RS & 496 & 31 & 6,24 \\
\cline { 2 - 5 } & SC & 293 & 17 & 5,76 \\
\hline \multicolumn{2}{c|}{ Sub. Total } & 1188 & 63 & 5,29 \\
\hline \multirow{2}{*}{$\begin{array}{c}\text { Centro- } \\
\text { Oeste }\end{array}$} & GO & 246 & 9 & 3,66 \\
\cline { 2 - 5 } & MS & 78 & 4 & 5,06 \\
\cline { 2 - 5 } & MT & 141 & 4 & 2,84 \\
\hline \multicolumn{2}{c|}{ Sub. Total } & 465 & 17 & 3,65 \\
\hline \multicolumn{2}{c|}{ Total } & 5569 & 240 & 4,31 \\
\hline
\end{tabular}

Fonte: IBGE para dados dos estados e municípios e Ministério do Esporte para o PELC.

Como pode ser observado na tabela 1, a participação dos estados é muito diferenciada. $\mathrm{O}$ dado negativo foi que em dez anos nenhum município do Amapá implementou o programa, sem que o governo central aparentemente buscasse qualquer estratégia para melhorar essa realidade. Apenas 4 estados tiveram descentralização acima de 10\% de suas prefeituras: Acre, Rondônia, Roraima e Rio de Janeiro. Abaixo de 5\% foram 14 estados. Esses resultados indicam que o programa foi incapaz de garantir um padrão mínimo de implementação. O desempenho de todos os estados do Nordeste é incompatível com a natureza do programa.

Tabela 2. Distribuição dos municípios que descentralizaram o PELC por IDH.

\begin{tabular}{c|c|c|c|c|c}
\hline IDH & Municípios & $\%$ & Mun. PELC & $\%$ & $\begin{array}{c}\text { Descentralização } \\
(\%)\end{array}$ \\
\hline MA & 32 & 0,58 & 0 & 0,00 & 0 \\
A & 1367 & 24,57 & 14 & 5,83 & 1,02 \\
M & 2233 & 40,13 & 61 & 25,42 & 2,73 \\
B & 1889 & 33,95 & 151 & 62,92 & 7,99 \\
MB & 43 & 0,77 & 14 & 5,83 & 32,56 \\
Total & 5564 & 100 & 240 & 100 & 4,31 \\
\hline
\end{tabular}

Fonte: Dados da pesquisa. $\mathrm{MA}=$ muito alto; $\mathrm{A}=$ alto; $\mathrm{M}=$ médio; $\mathrm{B}=$ baixo; $\mathrm{MB}=$ muito baixo.

A distribuição dos municípios por IDH é capaz de indicar aqueles municípios que conseguem garantir melhores condições de vida a seus munícipes, mesmo reconhecendo que há bolsões de pobrezas nos municípios de maior desenvolvimento 
econômico. É razoável pensar que os municípios com IDH Baixo e Muito Baixo sejam alvos prioritários das políticas sociais.

O que a tabela 2 nos apresenta é uma realidade importante para o desempenho do programa. Na distribuição do IDH, a grande maioria dos municípios não é considerável vulnerável, vez que se encontra entre o IDH Médio, Alto e Muito Alto (65,28\%). Apenas 34,72\% podem ser considerados vulneráveis. O PELC concentrou seus recursos no nível de maior vulnerabilidade, $68,75 \%$ dos municípios que descentralizaram o programa. Nesse sentido, parece que o menor desenvolvimento econômico e social foi fator potencializador dos convênios estabelecidos pelo programa nos dez primeiros anos de implementação.

Outro aspecto positivo importante da descentralização do PELC é o fato de que o nível de IDH que obteve o melhor resultado foi o IDH Muito Baixo. O nível mais baixo de desenvolvimento humano, com $32,56 \%$. O segundo melhor resultado se deu no IDH Baixo, 7,99\%.

Tabela 3: Distribuição dos municípios que descentralizaram o PELC por classe populacional.

\begin{tabular}{c|c|c|c|c|c}
\hline Classe Pop. & Municípios & $\%$ & Mun. PELC & $\%$ & $\begin{array}{c}\text { Descentralização } \\
(\%)\end{array}$ \\
\hline CP1 & 1301 & 23,38 & 18 & 7,50 & 1,38 \\
CP2 & 1212 & 21,78 & 28 & 11,67 & 2,31 \\
CP3 & 1400 & 25,16 & 24 & 10 & 1,71 \\
CP4 & 1043 & 18,75 & 32 & 13,33 & 3,07 \\
CP5 & 325 & 5,84 & 32 & 13,33 & 9,85 \\
CP6 & 245 & 4,40 & 78 & 32,50 & 31,84 \\
CP7 & 38 & 0,68 & 28 & 11,67 & 73,68 \\
\hline
\end{tabular}

Fontes: Dados da pesquisa.

Em relação à classe populacional, as três primeiras classes populacionais (municípios até 20 mil habitantes) concentram 70,34\% dos municípios brasileiros. Como pode ser percebido na tabela 3, há relação inversa entre tamanho e implementação do PELC. Os municípios acima de 50 mil habitantes concentram 
$57,08 \%$ dos municípios que implementaram o programa. Isso significa que as cidades maiores têm melhores condições para conveniarem com o governo federal, que fica ainda mais evidente ao relacionar com o número de convênios por cidade, ou seja, a quantidade de convênios por porte de cidade aumenta essa distância. Uma hipótese seria uma possível melhor capacitação dos gestores de cidades maiores e a influência política das cidades metropolitanas na decisão dos gestores na definição dos municípios contemplados

Na comparação horizontal é possível perceber que o tamanho da cidade interfere na descentralização do PELC. A capacidade de implementação das cidades menores é menor do que 5\%. Apesar de serem a maioria, apresentam enormes dificuldades para conveniarem com o Ministério do Esporte. Já as cidades maiores há um vetor que acompanha o tamanho da população: alcança $9,85 \%$ na CP5 e chega até $72,97 \%$ na CP7. Isso significa que os municípios maiores possuem melhores condições para conveniarem com o programa.

Durante o período, a implementação do programa não respondeu de forma a garantir ganhos crescentes. A baixa alocação de recursos no programa explica parte dessa realidade (CASTRO, 2016). Como observado na tabela 4, em 2003 o número de prefeituras que implementaram o programa foi de $10(0,18 \%)$ e, no último, $29(0,52 \%)$. Apenas em dois anos, 2008 e 2010, o PELC rompeu a barreira dos 100 municípios conveniados com o Ministério do Esporte $[104 \quad(1,87 \%)$ e $111 \quad(1,99 \%)$, respectivamente]. Não se identificou padrão no que diz respeito ao número de conveniamento/ano com as prefeituras.

Tabela 4. Evolução da participação das prefeituras na implementação do PELC

\begin{tabular}{l|l|l|l|l|l|l|l|l|l|l}
\hline Ano & 2003 & 2004 & 2005 & 2006 & 2007 & 2008 & 2009 & 2010 & 2011 & 2012 \\
\hline PELC & 10 & 18 & 22 & 38 & 57 & 104 & 42 & 111 & 15 & 29 \\
\hline
\end{tabular}


Fonte: Dados da pesquisa.

No período foram efetivados 446 convênios para descentralização do PELC junto às prefeituras. Das 240 prefeituras que implementaram o programa, $64,58 \%(\mathrm{n}=$ 155) dos convênios foram celebrados uma única vez no município; outros $16,25 \%$ ( $\mathrm{n}=$ 39) garantiram dois convênios por município; $9,16 \%(n=22)$ garantiram três convênios por município. Com relação aos municípios que tiveram mais de 4 convênios:

Tabela 5. Número de convênios do PELC por cidade

\begin{tabular}{|c|c|c|}
\hline $\mathrm{N}^{\mathrm{o}}$ convênios & $\mathrm{N}^{\mathrm{o}}$ cidades & Cidades \\
\hline 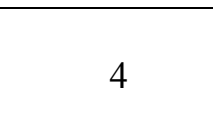 & 10 & $\begin{array}{l}\text { Rio Branco (AC), Maceió (AL), Manaus (AM), Vitória (ES), Belo } \\
\text { Horizonte (MG), Olinda (PE), Canoas (RS), Feliz (RS), Ivoti } \\
\text { (RS), Novo Hamburgo (RS), }\end{array}$ \\
\hline 5 & 4 & Cuiabá (MT), Santarém (PA), Belém (PA), \\
\hline 6 & 3 & Ipatinga (MG), Niterói (RJ), Porto Alegre (RS) \\
\hline 7 & 1 & Natal (RN) \\
\hline 8 & 1 & Santa Maria (RS) \\
\hline 9 & 1 & Queimados (RJ) \\
\hline 10 & 2 & Recife (PE), Volta Redonda (RJ) \\
\hline 12 & 1 & Rio de Janeiro (RJ) \\
\hline 13 & 1 & Fortaleza $(\mathrm{CE})$ \\
\hline
\end{tabular}

Fonte: Dados da pesquisa.

Como pode ser percebido na tabela 5, os municípios que firmaram mais de 4 convênios possuem algumas características importantes:

a) Capitais de estados: 13 .

b) Das não capitais, 41,66\% $(\mathrm{n}=5)$ são cidades do Rio Grande do Sul.

c) Apenas 1 município não é de região metropolitana: Feliz (RS).

Esses dados permitem observar que o aumento no número de convênios está associado a características muitos específicas dos municípios brasileiros. As capitais, os municípios das regiões metropolitanas e municípios gaúchos tiveram condições diferenciadas para implementarem o PELC com mais de 4 convênios. As capitais, a maioria com uma estrutura organizativa para promoverem as políticas públicas de 
esporte e lazer, reúnem um conjunto de elementos que, provavelmente, não estão presentes nas outras cidades. As regiões metropolitanas parecem interferir positivamente na difusão do programa. A elevada participação das cidades do Rio Grande do Sul pode estar associada a certa interferência (estímulo à adesão) de uma personagem política de elevado trânsito, Secretaria Nacional da SNDEL (de 2006 a 2011) e Secretaria Municipal de Esporte, Recreação e Lazer de Porto Alegre de 1993 a 2004. Sua estatura política e trânsito poderia ter influenciado um maior engajamento das prefeituras gaúchas.

\section{Considerações Finais}

Políticas descentralizadas em ambientes federados produzem diferenças na implementação, pois as instituições políticas afetam a distribuição de recursos (MARCH; OLSEN, 2008; GIBSON; CALVO; FALLETI, 2003). Apesar de ser uma política social que objetiva diminuir desigualdades, os gatilhos institucionais (desenho do programa, incentivos e interesses políticos em jogo) podem produzir realidade distinta.

No que diz respeito ao perfil, o estudo buscou caracterizar o programa a partir da região, dos estados participantes, do nível de desenvolvimento econômico e do tamanho e obteve os seguintes resultados: a) as regiões apresentaram baixo desempenho na implementação do programa. O destaque negativo ficou com a região Nordeste que obteve o menor percentual de convênios/município; b) os municípios do estado do Amapá não conseguiram estabelecer convênio com o PELC em dez anos e os estados da região Nordeste apresentaram desempenho muito abaixo da média nacional; c) o menor desenvolvimento econômico e social foi fator potencializador dos convênios 
estabelecidos pelo programa; d) os municípios maiores possuem melhores condições para conveniarem mais vezes com o programa. No que diz respeito ao perfil dos municípios prevalece a seguinte realidade: ser das regiões Norte, Sul, Sudeste e CentroOeste, de municípios de menor IDH e de cidades maiores.

Dos municípios que conquistaram mais de 4 convênios prevalecem as seguintes características: ser de capitais, de municípios das regiões metropolitanas do estado do Rio Grande do Sul. No entanto, o resultado mais emblemático da descentralização do PECL nos dez primeiros anos de implementação é a baixíssima adesão das prefeituras.

Considerando o perfil dos municípios que descentralizaram o PELC apontado no presente estudo, parece importante que pesquisas futuras tentem compreender os motivos que estimulam ou inibem os gestores públicos de implementar o PELC em seus respectivos municípios.

\section{REFERÊNCIAS}

ALMEIDA, M. H. T. Federalismo e políticas sociais. Revista Brasileira de Ciências Sociais, São Paulo, v. 10, n. 28, p. 88-108, 1995. 40. Jun, 2005.

. Recentralizando a federação? Revista Sociologia Política. Curitiba, 24, p. 29-

AREIAS, Keni Tatiana Vazzoler; BORGES, Carlos Nazareno Ferreira. As políticas públicas de lazer na mediação entre estado e sociedade: possibilidades e limitações. Revista Brasileira de Ciências do Esporte, v. 33, n. 3, 2011.

ARRETCHE, M. Federalismo e igualdade territorial: uma contradição em termos? Dados, Rio de Janeiro, v. 53, n. 3, p. 587-620, 2010.

.; MARQUES, E. Condicionantes locais da descentralização das políticas de saúde. In: HOCHMAN, G.; ARRETCHE, M.; MARQUES, E. (org.) Políticas públicas no Brasil. Rio de Janeiro: Ed. FIOCRUZ, 2007. p. 173-204.

ATHAYDE, Pedro; MASCARENHAS, Fernando; SALVADOR, Evilásio. Primeiras aproximações de uma análise do financiamento da política nacional de esporte e lazer no Governo Lula. Revista Brasileira de Ciências do Esporte, v. 37, n. 1, p. 2-10, 2015. 
BONALUME, C.R. (org.). Gestão de convênio dos Núcleos do Programa Esporte e Lazer da Cidade PELC e PRONASCI. Brasília: Fields, 2011.

. O paradigma da intersetorialidade nas políticas públicas de esporte e lazer.

Licere. Belo Horizonte, v. 14, n. 1, p. 1-26, mar. 2011.

BRASIL. Constituição da República Federativa do Brasil de 1988. Disponível em http://www.planalto.gov.br/ccivil_03/constituicao/constituicao.htm . Acesso em: jun. 2016.

CASTRO, S. B. E. de. Políticas públicas para o esporte e lazer e o ciclo orçamentário brasileiro (2004-2011): prioridades e distribuição de recursos durante os processos de elaboração e execução orçamentária. 378 f. Tese (Doutorado em Educação Física) - Universidade Federal do Paraná, Curitiba, 2016.

GIBSON, E. L.; CALVO, E. F.; FALLETI, T. G. Federalismo realocativo: sobrerepresentação legislativa e gastos públicos no hemisfério ocidental. Opinião Pública, Campinas, v. 9, n. 1, p. 98-123, 2003.

GOELLNER, Silvana V.; VOTRE, Sebastião ; MOURÃO, Ludmila ; FIGUEIRA, Márcia Luiza Machado . Lazer e gênero nos programas de esporte e lazer das cidades. Licere, v. 13, p. 2-23, 2010.

IBGE, 2006. Perfil dos municípios brasileiros: esporte. Rio de Janeiro: IBGE, 2006.

LINHALES, M. A. São as políticas públicas para a educação física/esportes e lazer, efetivamente políticas sociais? Motrivivência, Florianópolis, n. 11, p.71-81, set. 1998.

MARCH, James G; OLSEN, Johan P. Neo-institucionalismo: fatores organizacionais na vida política. Revista Sociologia Política, Curitiba, v. 16, n. 31, p. 121-142, nov. 2008.

MARQUES, E., ARRETCHE, M. Condicionantes Locais da descentralização das políticas de saúde. Caderno CRH. Salvador. N. 39, p. 55-81. jul/dez.2003.

MATIAS, Wagner. Política social de esporte e lazer no governo Lula: o Programa Esporte e Lazer da Cidade. Revista SER Social, v. 16, n. 34, p. 134, 2014.

MENDES, A. D.; AZEVEDO, P. H. Políticas públicas de esporte e lazer \& políticas públicas educacionais: promoção da educação física dentro e fora da escola ou dois pesos e duas medidas? Rev. Bras. Ciênc. Esporte 2010, vol.32, n.1 p.127-142.

MIRANDA, Ricardo Nunes de; MENDES, Marcos. Municípios em extrema pobreza: só dinheiro não resolve. 2004. Disponível em: https://www12.senado.leg.br/publicacoes/estudos-legislativos/tipos-de-estudos/textospara-discussao/td-15-municipios-em-extrema-pobreza-so-dinheiro-nao-resolve. Acesso em: 25 jan. 2017.

RIBEIRO, Leandro Molhano; FARIA, Carlos Aurélio Pimenta de. Federalismo, governo local e políticas sociais no Brasil entre 1996 e 2004. In: Federalismo e políticas públicas no Brasil. Editora Fiocruz, 2013. p. 151-177. 
RODDEN, J. Federalismo e descentralização em perspectiva comparada: sobre significados e medidas. Revista Sociologia e Política, Curitiba, v. 24, p. 9-27, jun. 2005 .

RUA, Maria das Graças. Análise de políticas públicas: conceitos básicos. Manuscrito, elaborado para el Programa de Apoyo a la Gerencia Social en Brasil. Banco Interamericano de Desarrollo: INDES, 1997.

SANTOS, Edmilson Santos; STAREPRAVO, Fernando Augusto; SOUZA NETO, Marina Silva. Programa Segundo Tempo e o vazio assistencial na região nordeste. Movimento, v. 21, n. 3, p. 759, 2015.

SECCHI. L. Políticas Públicas - Conceitos, Esquemas de Análise, Casos Práticos. Cengage Learning. 2011.

SOUSA, E. S. D.; NORONHA, V.; RIBEIRO, C. A.; TEIXEIRA, D. M. D.; FERNANDES, D. M.; VENÂNCIO, M. A. D. Sistema de monitoramento \& avaliação dos programas Esporte e Lazer da Cidade e Segundo Tempo do Ministério do Esporte. Belo Horizonte: O Lutador, 2010.

SOUZA, Celina Federalismo e Descentralização na Constituição de 1988: Processo Decisório, Conflitos e Alianças. Dados, Rio de janeiro, v. 44, nº 3, p. 513-560, 2001.

STAREPRAVO, F. A. Políticas públicas de esporte e lazer no Brasil: aproximações, intersecções, rupturas e distanciamentos entre os subcampos político/burocrático e científico/acadêmico. Tese (Doutorado em Educação Física) - Departamento de Educação Física, Universidade Federal do Paraná. Curitiba, 2011.

TERRA, A. M. et al. As conferências nacionais do esporte: avanços e limites na construção de políticas de esporte e lazer. In: CONGRESSO BRASILEIRO DE CIÊNCIAS DO ESPORTE, 16.; CONGRESSO INTERNACIONAL DE CIÊNCIAS DO ESPORTE, 3., 2009, Salvador. Anais... Salvador, 2009. Disponível em: $<$ http://www.rbceonline.org.br/congressos/index.php/CONBRACE/XVI/paper/view/77 5/806>. Acesso em: 29 jan. 2017.

VIEIRA, Larissa Haddad Souza; SILVEIRA, Suely de Fátima Ramos . Programa Esporte e Lazer da Cidade: Qual seu Desempenho?. In: IV Encontro de Administração Pública e Governança - EnAPG 2010, 2010, Vitória. IV Encontro de Administração Pública e Governança - EnAPG 2010, Anais... Vitoria, 2010.

\section{Endereço dos Autores:}

Edmilson Santos Santos

Rua Clóvis Beviláqua 160/02

Salvador - BA - 41.603-120

Endereço Eletrônico: edmilson.santos@univasf.edu.br 
Fernando Augusto Starepravo

Departamento de Educação Física

Avenida Colombo, n. 5.790 Bloco M-06 - Sala 002

Campus Universitário

Maringá - PR - 87.020-900

Endereço Eletrônico: fernando.starepravo@hotmail.com

\section{Edson Hirata}

Av. Armelindo Trombini, 3087

Campo Mourão - PR - 87.309-097

Endereço Eletrônico: chinahirata@gmail.com 